\title{
CAEP 2014 Academic Symposium: "How to make research succeed in your department: Promoting excellence in Canadian emergency medicine resident research"
}

Lisa A. Calder, MD, MSc** ${ }^{\dagger}$; Riyad B. Abu-Laban, MD, MHSc ${ }^{\ddagger}$; Jennifer D. Artz, PhD ${ }^{\S}$; Shelley McLeod, $\mathrm{MSc}^{\text {T; }}$ Barbara Blackie, MD**; Bijon Das, MD**; Robert Woods, MD, MMed ${ }^{\dagger \dagger}$; Jeffrey J. Perry, MD, $\mathrm{MSc}^{*}$; Christian Vaillancourt, MD, $\mathrm{MSc}^{*{ }^{+}}$; Ian G. Stiell, MD, $\mathrm{MSc}^{*{ }^{\dagger}}$; Jason R. Frank, MD, MEd ${ }^{*}$

\section{ABSTRACT}

Objectives: To characterize the current state of Canadian emergency medicine (EM) resident research and develop recommendations to promote excellence in this area.

Methods: We performed a systematic review of MEDLINE, Embase, and ERIC using search terms relevant to EM resident research. We conducted an online survey of EM residency program directors from the Royal College of Physicians and Surgeons of Canada (RCPSC) and College of Family Physicians of Canada (CFPC). An expert panel reviewed these data, presented recommendations at the Canadian Association of Emergency Physicians 2014 Academic Symposium, and refined them based on feedback received.

Results: Of 654 potentially relevant citations, 35 articles were included. These were categorized into four themes: 1) expectations and requirements, 2) training and assessment, 3) infrastructure and support, and 4) dissemination. We received 31 responses from all 31 RCPSC-EM and CFPC-EM programs. The majority of EM programs reported requiring a resident scholarly project; however, we found wide-ranging expectations for the type of resident research performed and how results were disseminated, as well as the degree of completion expected. Although $93 \%$ of RCPSC-EM programs reported providing formal training on how to conduct research, only $53 \%$ of CFPC-EM programs reported doing so. Almost all programs (94\%) reported having infrastructure in place to support resident research, but the nature of support was highly variable. Finally, there was marked variability regarding the number of resident-published abstracts and manuscripts.

Conclusions: Based on the literature, our national survey, and discussions with stakeholders, we offer 14 recommendations encompassing goals, expectations, training, assessment, infrastructure, and dissemination in order to improve Canadian EM resident research.

\section{RÉSUMÉ}

Objectifs: L'étude visait à caractériser l'état actuel de la recherche menée par les résidents en médecine d'urgence (MU) au Canada et à élaborer des recommandations afin de favoriser l'excellence dans le domaine.

Méthode: Les auteurs ont procédé à une revue systématique dans MEDLINE, Embase et ERIC à l'aide de termes d'interrogation concernant la recherche menée par les résidents en MU. Une enquête en ligne a également été réalisée parmi les directeurs de programme de résidence en $\mathrm{MU}$ du Collège royal des médecins et chirurgiens du Canada (CRMCC) et du Collège des médecins de famille du Canada (CMFC). Un groupe d'experts a examiné les données recueillies, a présenté des recommandations à l'occasion du Symposium sur les affaires universitaires de l'Association canadienne des médecins d'urgence de 2014 et les a reformulées en tenant compte des observations reçues.

Résultats: La recherche a permis de relever 654 mentions potentiellement pertinentes et de sélectionner 35 articles. Ceux-ci ont été divisés en quatre grands thèmes: 1) les attentes et les exigences; 2) la formation et l'évaluation; 3) l'infrastructure et le soutien; 4) la diffusion. Tous les directeurs de programme de MU du CRMCC et du CMFC, soit 31, ont répondu à l'enquête. On exige, dans la plupart des programmes, un projet de recherche érudite par les résidents; toutefois, il existe un large éventail de possibilités quant au type de recherche, aux formules de diffusion des résultats et

From the *Department of Emergency Medicine, University of Ottawa, Ottawa, ON; †Clinical Epidemiology Program, Ottawa Hospital Research Institute, Ottawa, ON; ¥Department of Emergency Medicine and Vancouver Coastal Health Research Institute Centre for Clinical Epidemiology and Evaluation, University of British Columbia, Vancouver, BC; §Canadian Association of Emergency Physicians, Ottawa, ON; IDepartment of Medicine, Division of Emergency Medicine, The University of Western Ontario, London, ON; **Department of Emergency Medicine, Dalhousie University, Halifax, NS; and T+Department of Emergency Medicine, University of Saskatchewan, Saskatoon, SK.

Correspondence to: Dr. Lisa Calder, Ottawa Hospital, Civic Campus, Clinical Epidemiology Unit, F658,1053 Carling Ave., Ottawa, ON K1Y 4E9; Email: Icalder@ohri.ca 
au degré attendu de réalisation. Tandis que $93 \%$ des directeurs de programme du CRMCC ont indiqué donner de la formation structurée sur la manière de faire de la recherche, seuls $53 \%$ des directeurs de programme du CMFC ont indiqué en faire autant. Dans presque tous les programmes (94\%), I'on dispose d'une infrastructure de soutien à la recherche menée par les résidents, mais la nature du soutien varie énormément. Enfin, il y a des différences importantes en ce qui concerne le nombre de résumés et de textes publiés par les résidents.
Conclusions: Compte tenu de la documentation, de l'enquête nationale et des discussions avec les parties intéressées, le groupe a élaboré 14 recommandations sur les buts, les attentes, la formation, l'évaluation, l'infrastructure et la diffusion afin d'améliorer la recherche menée par les résidents en MU au Canada.

Keywords: curriculum, education, emergency medicine, research, resident, training

\section{INTRODUCTION}

\section{Background}

Scholarly activities and, in particular, research are critical to advance modern medicine. ${ }^{1}$ Although still a relatively new specialty, emergency medicine (EM) has a rich history of practice-changing evidence development and training enhancement in order to advance the field. ${ }^{2}$ In medical disciplines, foundational research literacy is considered a core competence. ${ }^{3}$ For residents, early involvement in research has been shown to enable future scholarly work. ${ }^{4}$ Scholarly projects during residency represent opportunities to develop focused research questions, to plan study protocols, to execute data collection, as well as to analyse and interpret the data. The dissemination of results represents an opportunity for residents to enhance written and oral communication skills. These experiences also impart essential critical appraisal skills and prepare those with academic inclinations to be research producers. ${ }^{5}$

\section{Dual college nature of Canadian EM training}

Canada is unique with two distinct training streams for EM. Each program has a different philosophy and capacity to provide resident research education, and each was considered in the recommendations development. The most significant difference is training time (i.e., 5 years in the Royal College of Physicians and Surgeons of Canada [RCPSC-EM] programs and 1 year of EM training following 2 years of family medicine residency in the College of Family Physicians of Canada [CFPC-EM] programs). Beyond the challenges for longitudinal scholarly projects, there are constraints to achieve EM clinical competence during the training time allotted for CFPC-EM residents.

\section{Importance}

Resident research is essential for developing future EM researchers and advancing the science of EM, both of which ultimately improve clinical care for patients. Given the diversity of the emergency department patient population and the challenges of providing leading edge emergency care, emergency physicians seek evidence to guide clinical decisions. Currently, for Canadian EM residency programs, the following elements of resident research are unknown: nature of research education and how it is provided, type of exposure to scholarly projects, and resulting scholarly outputs.

\section{Objectives}

We sought to characterize the current state of Canadian EM resident research and develop a series of pragmatic recommendations to promote excellence in this area.

\section{METHODS}

\section{Design}

At the direction of the Canadian Association of Emergency Physicians (CAEP) Academic Section, we assembled an expert panel and advisory committee, which included representation from RCPSC-EM and CFPCEM programs from across the country. We systematically reviewed the existing literature on EM resident research and performed a national survey of the current state of resident research education and output among Canadian EM residency programs. Using these data, we developed preliminary recommendations via a consensus process with experts in EM education and research. These recommendations were refined from discussions at a national academic symposium held at the CAEP 2014 Conference. We obtained approval for the survey from 
The University of Western Ontario Research Ethics Board for Health Sciences Research Involving Human Subjects.

\section{Systematic literature review}

With the assistance of a research librarian, we developed a search strategy using predefined Medical Subject Headings $(\mathrm{MeSH})$ and free text words: research\$, peer review, publication\$, publishing, educat $\$$, training $\$$, academic $\$$, scholar $\$$, project, education, residen $\$$, emergency service, critical care, and trauma. Restricting language to English or French, we searched MEDLINE, Embase, and ERIC using Ovid from 1946 to November 2013. All potentially relevant citation titles, abstracts, and then full articles were independently reviewed by two authors (LC, SM), and disagreements were resolved by consensus. We included all articles that were relevant to EM resident research, consisted of descriptions or evaluations of resident research programs, or described standards for resident research. We excluded editorials, letters to the editor, and articles about a single resident research project or research programs for fellows. We categorized the resulting articles into themes and distributed them among panel members for critical appraisal and summary.

\section{Survey}

Our literature search did not encounter any survey instruments to determine the current state of EM resident research. Through an iterative process, we developed a 36-item online survey instrument designed to address four main themes arising from our literature search: 1) expectations and requirements, 2) training and assessment, 3) infrastructure and support, and 4) dissemination. Prior to distribution, we piloted the survey among panel members. We sent an email request with a survey link to program directors and assistant program directors for all RCPSC-EM and CFPC-EM programs. We excluded subspecialty programs, such as pediatric EM, prehospital medicine, ultrasound, simulation, and medical education. The link included a letter indicating that responses would be anonymized and reported in aggregate form only. Respondents received email reminders, and, in some cases, resident research coordinators and research directors were contacted to obtain responses.
We analysed the resulting data using descriptive statistics reporting means, medians, and proportions.

\section{Recommendation development}

We derived the recommendations by group consensus in an iterative fashion after discussion of the literature and generated survey data. Once refined, we distributed the draft recommendations for review and feedback to the Specialty Committee of the RCPSC and the Emergency Medicine Special Interest Focused Practice Committee of the CFPC. We also distributed the draft recommendations to the CAEP Resident Section. Finally, we presented the draft recommendations for discussion at an academic symposium at the CAEP 2014 Conference, which was attended by 80 individuals, including EM program directors, researchers, administrators, attending emergency physicians, and residents. The final recommendations were subsequently revised based on the feedback obtained.

\section{Definitions}

The committee recognized early on in discussions that there was a need for clear definitions of a scholarly project and the desired levels of competence for residents completing such projects. We developed the definitions described in Boxes 1 and 2 through an iterative process, including feedback from the CAEP Academic Symposium.

\section{Box 1. Proposed definition of a scholarly project}

Scholarly project: an educational method to acquire competencies for academic inquiry via a systematic approach to define a relevant problem and design a response, with reference to previous literature and theory.

\section{Box 2. Proposed levels of competence}

1. Critical appraiser of research: This physician can demonstrate research literacy and the ability to critically appraise the evidence, incorporating this into evidence-based clinical decision making.

2. Research contributor: This physician is a skilled research consumer and participates in contributing to original research, albeit not as the primary investigator.

3. Research producer: This physician is a skilled research consumer and possesses advanced training in research methods, engaging in the process of generating original ideas, obtaining funding, executing research, and disseminating it in a scholarly fashion. 


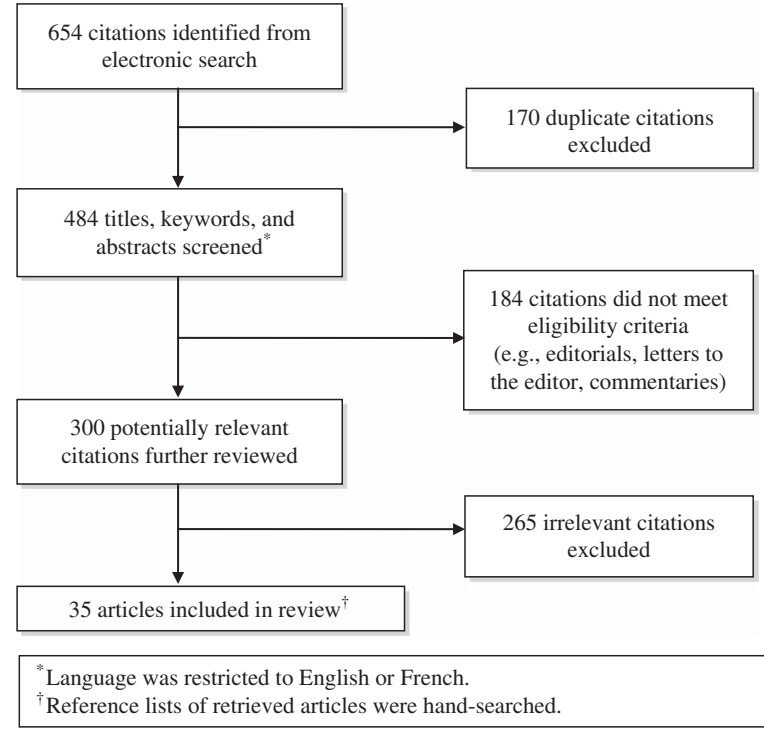

Figure 1. Flow of article selection from systematic literature review of MEDLINE, Embase, and ERIC.

Table 1. Characteristics of 31 responding Canadian EM residencies

\begin{tabular}{|c|c|c|c|c|}
\hline & \multicolumn{2}{|c|}{$\begin{array}{c}\text { RCPSC-EM } \\
\quad(n=14)\end{array}$} & \multicolumn{2}{|c|}{$\begin{array}{c}\text { CFPC-EM } \\
(n=17)\end{array}$} \\
\hline & $n$ & & $n$ & \\
\hline Median number of residents* & 21 & & 8 & \\
\hline Range & $6-50$ & & $3-13$ & \\
\hline Required to complete a project & 11 & $79 \%$ & 13 & $76 \%$ \\
\hline Resident research coordinator & 10 & $71 \%$ & 9 & $53 \%$ \\
\hline
\end{tabular}

Table 2. Types of scholarly projects for 31 Canadian EM residencies

\begin{tabular}{|c|c|c|c|c|}
\hline & \multicolumn{2}{|c|}{$\begin{array}{l}\text { RCPSC-EM } \\
(n=14)\end{array}$} & \multicolumn{2}{|c|}{$\begin{array}{c}\text { CFPC-EM } \\
(n=17)\end{array}$} \\
\hline & $n$ & & $n$ & \\
\hline Prospective data collection & 10 & $71 \%$ & 6 & $35 \%$ \\
\hline Research protocol & 9 & $64 \%$ & 8 & $47 \%$ \\
\hline Quality assurance & 9 & $64 \%$ & 8 & $47 \%$ \\
\hline Educational project & 9 & $64 \%$ & 6 & $35 \%$ \\
\hline Critical appraisal of a topic & 8 & $57 \%$ & 10 & $59 \%$ \\
\hline Survey & 8 & $57 \%$ & 4 & $24 \%$ \\
\hline Health records review & 6 & $43 \%$ & 6 & $35 \%$ \\
\hline Other & 1 & $7 \%$ & 2 & $12 \%$ \\
\hline
\end{tabular}

\section{RESULTS}

\section{Systematic literature review}

Our search strategy yielded 654 potentially relevant citations. After elimination of duplicate abstracts $(n=170)$ and reports that did not satisfy inclusion criteria $(n=184)$, we reviewed 300 citation titles and abstracts then selected 35 articles (Figure 1), which were classified into themes: 1) expectations and requirements, 2) training and assessment, 3) infrastructure and support, and 4) dissemination.

\section{Survey}

We achieved a $100 \%$ response rate for our national survey of Canadian EM program directors (14 RCPSCEM, 17 CFPC-EM). Table 1 describes the program characteristics. The majority reported requiring residents to complete a scholarly project (76\% CFPC-EM and $79 \%$ RCPSC-EM).

For RCPSC-EM programs, the majority of projects involved prospective data collection $(71 \%)$, educational projects $(64 \%)$, quality assurance projects $(64 \%)$, surveys $(57 \%)$, critical appraisals of topics $(57 \%)$, or health records reviews (43\%) (Table 2). In contrast, the CFPC-EM program projects included critical appraisals of topics (59\%); development of research protocols (47\%), quality assurance projects (47\%) or health records reviews (35\%); prospective data collection $(35 \%)$; or education projects $(35 \%)$.

For both EM programs, more than half of them expected residents to prepare an abstract from their scholarly project, with the majority expecting submission locally. Very few of the CFPC-EM programs expected submission to national or international conferences (Table 3). In contrast, half of RCPSC-EM programs expected national conference submissions, and over half of these expected international venues. Just over half of the RCPSC-EM programs expected a manuscript to be prepared and submitted. Only two CFPC-EM programs expected manuscript preparation, and one expected manuscript submission.

Nearly all RCPSC-EM programs and half of CFPCEM programs reported providing formal training to residents on how to conduct research (Table 4), typically delivered by varying instructors from epidemiologists to EM faculty to non-faculty researchers. A wide variety of resources were reportedly available to residents on how to conduct resident research. In terms 


\begin{tabular}{|c|c|c|c|c|}
\hline \multirow[t]{3}{*}{$\begin{array}{l}\text { Table 3. Program } \\
\text { residencies }\end{array}$} & \multicolumn{4}{|c|}{ Canadian } \\
\hline & \multicolumn{2}{|c|}{$\begin{array}{c}\text { RCPSC-EM } \\
\quad(n=14)\end{array}$} & \multicolumn{2}{|c|}{$\begin{array}{c}\text { CFPC-EM } \\
(n=17)\end{array}$} \\
\hline & $n$ & & $n$ & \\
\hline Expected to prepare an abstract & 8 & $57 \%$ & 11 & $65 \%$ \\
\hline Expected to submit an abstract & 7 & $50 \%$ & 9 & $53 \%$ \\
\hline Locally & 6 & $86 \%$ & 9 & $100 \%$ \\
\hline National conference & 7 & $100 \%$ & 1 & $11 \%$ \\
\hline International conference & 4 & $57 \%$ & 0 & $0 \%$ \\
\hline Expected to prepare a manuscript & 8 & $57 \%$ & 2 & $12 \%$ \\
\hline Expected to submit a manuscript & 8 & $57 \%$ & 1 & $6 \%$ \\
\hline
\end{tabular}

Table 4. Formal education, resources, and infrastructure for 31 Canadian EM residencies

\begin{tabular}{|c|c|c|c|c|}
\hline \multirow{3}{*}{ Formal education } & \multirow{2}{*}{\multicolumn{2}{|c|}{$\begin{array}{l}\text { RCPSC- } \\
\text { EM } \\
(n=14) \\
n\end{array}$}} & \multirow{2}{*}{\multicolumn{2}{|c|}{$\begin{array}{l}\text { CFPC-EM } \\
(n=17) \\
n\end{array}$}} \\
\hline & & & & \\
\hline & 13 & $93 \%$ & 9 & $53 \%$ \\
\hline \multicolumn{5}{|l|}{ Providers of formal education } \\
\hline Epidemiologist & 7 & $50 \%$ & 1 & $6 \%$ \\
\hline Statistician & 5 & $36 \%$ & 2 & $12 \%$ \\
\hline EM faculty researcher & 12 & $86 \%$ & 9 & $53 \%$ \\
\hline EM faculty non-researcher & 4 & $29 \%$ & 2 & $12 \%$ \\
\hline Other* & 3 & $21 \%$ & 1 & $6 \%$ \\
\hline \multicolumn{5}{|l|}{ Resources } \\
\hline Locally derived research handbook & 3 & $21 \%$ & 3 & $18 \%$ \\
\hline Online resources for resident research & 4 & $29 \%$ & 3 & $18 \%$ \\
\hline Articles on resident research & 6 & $43 \%$ & 3 & $18 \%$ \\
\hline $\begin{array}{l}\text { Royal College Manual on Resident } \\
\text { Research }^{6}\end{array}$ & 5 & $36 \%$ & 1 & $6 \%$ \\
\hline Other** & 4 & $29 \%$ & 1 & $6 \%$ \\
\hline \multicolumn{5}{|l|}{ Infrastructure/support } \\
\hline Resident research coordinator & 10 & $71 \%$ & 9 & $53 \%$ \\
\hline Assistance with $\mathrm{REB}^{\dagger}$ application & 8 & $57 \%$ & 10 & $59 \%$ \\
\hline Methodological support & 7 & $50 \%$ & 12 & $71 \%$ \\
\hline Data entry support & 6 & $43 \%$ & 6 & $35 \%$ \\
\hline Statistical support & 8 & $57 \%$ & 13 & $76 \%$ \\
\hline Abstract submission support & 7 & $50 \%$ & 9 & $53 \%$ \\
\hline Poster development support & 7 & $50 \%$ & 10 & $59 \%$ \\
\hline Manuscript development support & 6 & $43 \%$ & 9 & $53 \%$ \\
\hline Other $^{\ddagger}$ & 2 & $14 \%$ & 2 & $12 \%$ \\
\hline No infrastructure & 1 & $8 \%$ & 0 & $0 \%$ \\
\hline \multicolumn{5}{|l|}{ Funding of staff positions } \\
\hline Department/division & 10 & $71 \%$ & 15 & $88 \%$ \\
\hline Other & 2 & $14 \%$ & 2 & $12 \%$ \\
\hline \multicolumn{5}{|c|}{$\begin{array}{l}\text { *PhD scientist, librarian, non-clinician researchers. } \\
{ }^{* *} \mathrm{NERD} \text { block, online listing of staff interests and projects, university postgraduate } \\
\text { resources, quality assurance resources. } \\
{ }^{+R E B}=\text { Research Ethics Board. } \\
\text { FSupport provided ad hoc by faculty, plans for a resident research coordinator, family } \\
\text { medicine department resources. }\end{array}$} \\
\hline
\end{tabular}

of assessment, 64\% of RCPSC-EM and 54\% of CFPCEM programs reported evaluating their resident scholarly projects. Less than half of the programs did so formally, and others used a hybrid approach (formal and informal). One half of RCPSC-EM and CFPC-EM programs reported performing individual assessments, and less than $20 \%$ of programs reported evaluating their overall resident research activities.

We found that a majority of programs reported infrastructure in place to support resident research. Most RCPSC-EM programs (83\%) reported having a resident research coordinator, as did half of CFPC-EM programs. However, the nature of support residents reportedly received for key stages of project execution was highly variable (Table 5). In most cases, funding for staffed positions to support resident research was internally derived.

Finally, in terms of dissemination of the results of resident research, we found a marked variability regarding programs' self-report of resident abstracts and manuscripts that appeared to be independent of program size (Figures 2 and 3).

\section{Academic symposium}

The importance of mentorship, clarification of the role of a research coordinator, importance of individual $v$. program-wide evaluations, and broadening the definition

Table 5. Infrastructure provided to residents

\begin{tabular}{|c|c|c|c|c|}
\hline & \multicolumn{2}{|c|}{$\begin{array}{c}\text { RCPSC-EM } \\
(n=14)\end{array}$} & \multicolumn{2}{|c|}{$\begin{array}{c}\text { CFPC-EM } \\
(n=17)\end{array}$} \\
\hline & $n$ & & $n$ & \\
\hline Infrastructure/support & 12 & $86 \%$ & 17 & $100 \%$ \\
\hline Resident research coordinator & 10 & $71 \%$ & 9 & $53 \%$ \\
\hline Assistance with REB ${ }^{\#}$ application & 8 & $57 \%$ & 10 & $59 \%$ \\
\hline Methodological support & 7 & $50 \%$ & 12 & $71 \%$ \\
\hline Data entry support & 6 & $43 \%$ & 6 & $35 \%$ \\
\hline Statistical support & 8 & $57 \%$ & 13 & $76 \%$ \\
\hline Abstract submission support & 7 & $50 \%$ & 9 & $53 \%$ \\
\hline Poster development support & 7 & $50 \%$ & 10 & $59 \%$ \\
\hline Manuscript development support & 6 & $43 \%$ & 9 & $53 \%$ \\
\hline Other* & 2 & $14 \%$ & 2 & $12 \%$ \\
\hline \multicolumn{5}{|l|}{ Funding of staff positions } \\
\hline Department/Division & 10 & $71 \%$ & 15 & $88 \%$ \\
\hline Other & 2 & $14 \%$ & 2 & $12 \%$ \\
\hline
\end{tabular}


of what constitutes dissemination of scholarly work were issues raised during the academic symposium.

\section{DISCUSSION AND RECOMMENDATIONS}

We found a paucity of literature describing the current state of EM resident research in Canada.

\section{Box 3. Recommendations}

\section{Expectations and Requirements Recommendations}

1.1. Specific clarification is recommended around the goals and exit competencies regarding research training and assessment for emergency medicine residents from both colleges, so they are clearly aligned with the college training objectives. The desired competency outcome (i.e., critical appraiser, research contributor, and/or research producer) and an explicit definition for scholarly project should be declared.

1.2. For the RCPSC-EM programs, a range of research opportunities should be available to meet all competency outcomes, including a stream for advanced research training (e.g., MSc or $\mathrm{PhD}$ ). The recently revised CanMEDS Scholar milestones are relevant to this process. 1.3. RCPSC programs should develop a research training curriculum for their residents matched to desired competency outcomes. 1.4. For the CFPC-EM programs, a clear path (i.e. explicit objectives and expectations) for those interested in further research training should be defined.

\section{Training and Assessment Recommendations}

2.1. The RCPSC should address the variability across its programs and consider the advantages of a structured research training curriculum offered early to provide residents more research opportunities. 2.2. Given the two family medicine years plus one emergency medicine year in CFPC-EM training, the CFPC should identify specific research training elements necessary to supplement the family medicine research training curriculum.

2.3. All residency programs should assess individual resident research projects as well as evaluate their resident research programs as a whole.

\section{Infrastructure and Support Recommendations}

3.1. All programs should strongly consider using a resident research coordinator to facilitate research ethics board application, project management, publication, and program evaluations.

3.2. Resident research programs should link to existing infrastructure within their institution (in other programs or medical departments) to assist residents with scholarly project design and statistical analysis. 3.3. All programs should dedicate research funding support toward resident research.

3.4. All programs should consider matching residents with research mentors (who can provide methodological and pragmatic support). This can also occur outside of the program and/or the institution.

\section{Dissemination Recommendations}

4.1. All residency programs should encourage their residents to broadly disseminate project results (whether by traditional publication or other peer-reviewed, citeable venues), including manuscript preparation by RCPSC residents and abstract presentation by all residents (at least locally, but ideally nationally).

4.2. Resident research abstracts and manuscript publications should be tracked as a metric for the evaluation of academic productivity, at least locally, but ideally nationally and/or internationally.
Most was more than 10 years old and US-based. Development and application of critical appraisal skills are inextricably linked to the development of research skills, and a recently published survey found that $85 \%$ of RCPS-EM programs have established evidence-based medicine curricula. ${ }^{7}$ One example of explicit training for resident research was a mixedmethods study describing a unique 1-month mandatory

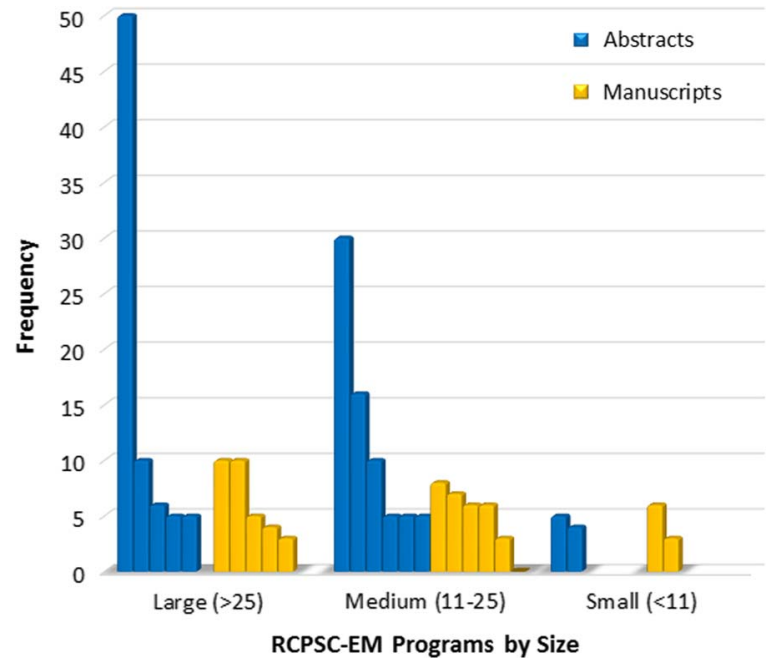

Figure 2. Number of abstracts and manuscripts reported by RCPSC-EM programs* over the past 3 years reported by the number of residents in the program, as large $(>25)$, medium (11-25), or small $(<11)$.

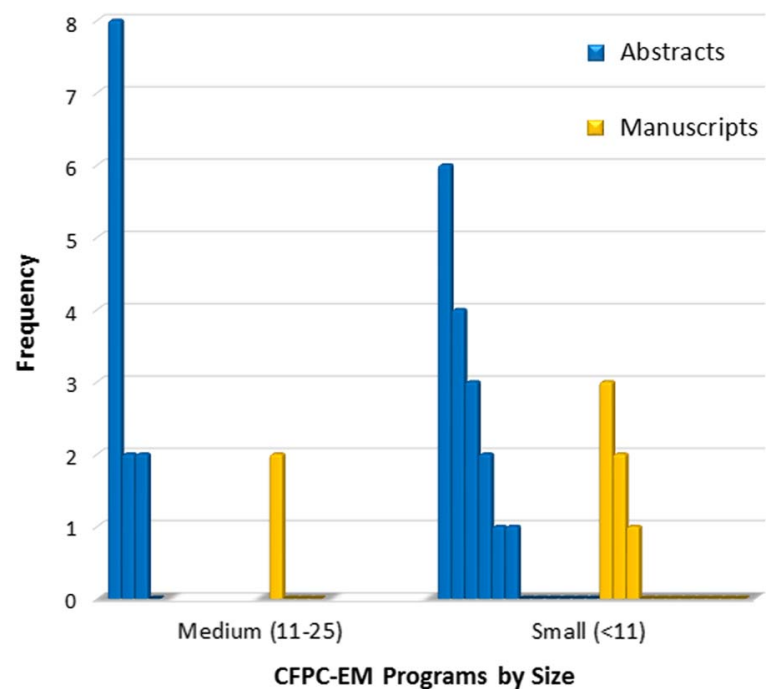

Figure 3. Number of abstracts and manuscripts reported by CFPC-EM programs* over the past 3 years reported by the number of residents in the program, as either medium $(11-25)$ or small $(<11)$. 
rotation for junior RCPSC-EM residents, called the NERD block (Novel Education in Research and Design). ${ }^{8}$

Our survey highlighted marked diversity in residency programs' self-report expectations, training, evaluation, infrastructure, and dissemination, not just between RCPSC-EM and CFPC-EM programs but also among them. The expected degree of project completeness also varied across programs. We found a lack of clarity in the goals and objectives of the scholarly project within EM residency. The research methods training that residents reportedly received was highly variable, indicating that a single consolidated resource repository would be helpful. Few residencies reported formally evaluating their resident research programs, and dissemination of resident research is inconsistent. Although a centrally mandated approach is likely undesirable, the variability across and within programs suggests that improvements are possible, which our panel believes could lead to increased academic and research productivity. Ultimately, enhancements to EM research would lead to ongoing improvements to patient care.

\section{Expectations and requirements recommendations (Box 3)}

\section{a. Relevant literature}

We sought to determine the requirements of both colleges for resident research. The RCPSC's Objectives of Training in EM describe a scholarly project requirement: "Complete at least one scholarly project that is suitable for peer reviewed publication or presentation at a national academic meeting, as attested by the Program Director."

The CFPC-EM programs are guided by the Specific Standards for Family Medicine Residency Programs Accredited by the CFPC: The Red Book, which states:

"The acquisition of critical appraisal skills is essential. Programs might require residents to complete an academic project. For those residents who wish to pursue an academic project (research, literature review, quality improvement), the program should provide the opportunity to do so." ${ }^{10}$ Because we found no further literature describing the expectations and requirements for EM resident research in Canada, our panel developed and refined a proposed definition of a scholarly project at the CAEP 2014 Academic Symposium (see Box 1).

\section{b. Relevant survey data}

The majority of program directors surveyed indicated that they require scholarly projects of their residents. The types of acceptable scholarly projects were felt to be appropriate, allowing for a diversity of designs. There were some programs, particularly CFPC-EM, which restricted projects to either critical topic appraisals or generation of a research protocol. We noted variability in expectations for dissemination, with most programs requiring an abstract submission to local venues and a smaller number to national or international conferences. An even smaller number required manuscript submission. Qualitative survey responses indicated that program directors felt that the key reasons for not requiring manuscript submission included lack of an RCPSC-EM or CFPC-EM requirement and insufficient time during the training program.

\section{Training and assessment recommendations}

\section{a. Relevant literature}

We found that much of the published literature is out of date and originated from the United States. Although several papers identified proposed curricula or identified a need for resident research training, they failed to account for recent improvements in epidemiology and critical appraisal education. ${ }^{11,12}$ The existing literature suggested that, although EM resident research training is important, it is still not ideal. No study demonstrated improvements from specific resident research training or evaluation of long-term outcomes, such as academic productivity, or pursuit of an academic career.

\section{b. Relevant survey data}

Our survey highlighted both differences and similarities between RCPSC-EM and CFPC-EM residency programs. Most RCPSC-EM programs (92\%) reported providing formal research education, in contrast to $50 \%$ of CFPC-EM programs. RCPSC-EM programs typically reported more extensive curricula, often including education from epidemiologists and statisticians, whereas CFPC-EM programs more frequently reported informal or optional research education. A number of CFPC-EM programs identified the 1-year training duration as a barrier. Two programs indicated that they rely, in part, on education provided during the two family medicine years. Most EM residency programs, especially the CFPC-EM, reportedly assessed resident research abilities, often via presentation at an EM research day.

\section{c. Best practices}

The RCPSC-EM residency research education initiative, NERD block, was identified as a unique program 
that delivers a 1-month comprehensive curriculum with four goals (obtaining research knowledge, obtaining critical appraisal skills, advancing a research project, and increasing resident/faculty collaborations). ${ }^{7}$ The program demonstrated pre- and post-improvement of research knowledge and may merit consideration by other RCPSC programs. Academic symposium attendees supported the notion of a longitudinal curriculum that matches to goals and competencies (Box 2).

\section{Infrastructure and support recommendations}

\section{a. Relevant literature}

There was a limited number of infrastructure and support studies related to EM resident research. Program director support, faculty size, resident research awards, and overall financial support were positively associated with resident research publications. ${ }^{13}$ Similarly, research funding and support (specifically at least two of a dedicated lab space, support for lab research assistant, dedicated research nurse or study coordinator, statistician or assistant with a $\mathrm{PhD}$ ) were positively associated with EM residents graduating and entering an academic career. ${ }^{14}$

\section{b. Relevant survey data}

We found that over $86 \%$ of the EM programs reported some form of infrastructure support, including $83 \%$ of RCPSC-EM and 53\% of CFPC-EM programs having resident research coordinators. Some survey respondents planned to hire a resident research coordinator. Most of the staffed positions to support resident research were internally funded.

\section{c. Academic symposium findings}

Academic symposium attendees endorsed the importance of a research coordinator, and several sites attributed increased research success to a coordinator. One caveat raised was limiting the scope of the role to facilitation, because it was felt to be important that residents still maintained responsibility for the work. Attendees also stressed the importance of mentorship for scholarly projects success, and a national network of mentors was suggested.

\section{Dissemination recommendations}

\section{a. Relevant literature}

Research publication remains an important measure of academic productivity. ${ }^{15}$ Henderson and Brestky retrospectively identified 3,551 EM articles published over a 7-year period where the academic affiliation of the first author was recorded to identify factors positively associated with the number of publications. Faculty size and program location were found to be independently associated with increased research publications. The authors suggested that programs with higher research productivity may also have more experienced research mentors and specific resources for residents and faculty.

\section{b. Relevant survey data}

Our survey results suggested that almost all Canadian EM residency programs have some infrastructure support and dedicated personnel for resident research. However, assistance for abstract submission, poster development, and manuscript preparation is markedly low in nearly half of programs. Internal funding to support resident research was reportedly available in 67\% CFPC-EM and 83\% RCPSC-EM programs, and was usually to offset conference travel costs. Although all RCPSC-EM programs and $94 \%$ of CFPC-EM programs hold a local EM "Research Day," only 67\% of CFPC-EM programs expected their residents to present. All of the RCPSC-EM and $63 \%$ of CFPC-EM programs reported having residents who presented abstracts over the past 3 years at national or international conferences (e.g., CAEP, Society for Academic Emergency Medicine). Over the past 3 years, the number of abstracts reported by RCPSC-EM programs ranged from 4 to 50, compared to 1 to 8 abstracts presented by CFPC-EM residents. Similarly, more RCPSC-EM programs (92\%) than CFPC-EM programs (38\%) reported publishing manuscripts.

\section{c. Academic symposium findings}

Academic symposium attendees suggested that 1) scholarly dissemination can be broadly defined, 2) future EM research producers should be strongly encouraged to publish during residency, and 3) expectations for dissemination should be matched to levels of competence (see Box 2).

\section{LIMITATIONS}

Although the literature search strategy we used was comprehensive, relevant articles may have been missed. The survey is potentially subject to recall bias, particularly for the number of published abstracts and manuscripts. Although the recommendations were developed from the literature, survey data, and input from stakeholders, key 
issues may not have emerged from academic symposium attendees or other consulted experts. The results are also limited, because subspecialties, including pediatric EM, were not included within the scope of this work.

\section{CONCLUSION}

As EM matures, the time is right to strengthen Canadian EM resident research. The future of Canadian EM research lies with our residents, and action should be taken to encourage resident research involvement and productivity. This includes 1) clear articulation by RCPSC and CFPC resident research goals, 2) clarification of the expectations and opportunities for future research critical appraisers and research producers, 3) boosting of existing training, 4) evaluations of resident research programs, 5) use of resident research coordinators, 6) linking with existing research infrastructure, 7) leveraging of internal academic funding sources to strengthen infrastructure, and 8) encouragement of the dissemination of high-quality research beyond local venues. These recommendations will assist RCPSC and CFPC, program directors, research directors, and residents to strive for excellence in Canadian EM resident research.

Acknowledgements: The authors would like to thank the advisory panel, including Tim Dalseg, Debra Eagles, and Avik Nath, as well as the librarian Alla Iansavitchen.

Competing interests: Dr. Riyad Abu-Laban, a core panel member and co-author, is also the rotation director of the 1-month "NERD Block" at the University of British Columbia research rotation discussed in the paper and lead author of the publication describing this. Dr. Abu-Laban provided input and perspective to the committee on the NERD Block rotation but was not involved in final decisions as to how this was characterized in the manuscript or the resulting final recommendations.

Dr. Jason Frank, a core panel member and co-author, was also involved in the development of the guide for The Royal College, The Royal College program directors handbook: a practical guide for leading an exceptional program (2014).

\section{REFERENCES}

1. Bensing J. Bridging the gap: the separate worlds of evidencebased medicine and patient-centered medicine. Patient Educ Couns 2000;39(1):17-25.
2. Suter RE. Emergency medicine in the United States: a systemic review. World 7 Emerg Med 2012;3(1):5-10.

3. Frank JR, Snell LS, Sherbino J, eds. The Draft CanMEDS 2015 Physician Competency Framework - Series III. Ottawa: The Royal College of Physicians and Surgeons of Canada; 2014.

4. Sanders AB, Fulginiti JV, Witzke DB. Factors influencing resident career choices in emergency medicine. Ann Emerg Med 1992;21(1):47-52.

5. Summers RL, Fish S, Blanda M, Terndrup T, Saem Research Directors' Interest Group. Assessment of the "scholarly project" requirement for emergency medicine residents: report of the SAEM Research Directors Workshop. Acad Emerg Med 1999;6(11):1160-5.

6. Harvey BJ, Lang ES, Frank JR. The Research Guide: A Primer for Residents, Other Health Care Trainees, and Practitioners. Ottawa: The Royal College of Physicians and Surgeons of Canada; 2011.

7. Bednarczyk J, Pauls M, Fridfinnson J, Weldon E. Characteristics of evidence-based medicine training in Royal College of Physicians and Surgeons of Canada emergency medicine residencies - a national survey of program directors. BMC Med Educ 2014;14:57.

8. Abu-Laban RB, Jarvis-Selinger S, Newton L, Chung B. Implementation and evaluation of a novel research education rotation for royal college of physicians and surgeons emergency medicine residents. CFEM 2013; 15(4):233-6.

9. The Royal College. The Royal College program directors bandbook: a practical guide for leading an exceptional program. Ottawa: The Royal College of Physicians and Surgeons of Canada; 2014.

10. College of Family Physicians of Canada. Standards for accreditation of residency training programs: family medicine; emergency medicine; enhanced skills; palliative medicine; 2013. Available at: http://www.cfpc.ca/uploadedFiles/Red\% 20Book\%20English.pdf.

11. Brautigan MW. A systematic approach to research curricula for emergency medicine residencies. 7 Emerg Med 1984; $1(5): 459-64$.

12. Olson JE, Hamilton GC, Angelos MG, et al. Objectives to direct the training of emergency medicine residents on off-service rotations: research. 7 Emerg Med 1992; 10(5):631-6.

13. Levitt MA, Terregino CA, Lopez BL, Celi C. A national profile of resident research programs in emergency medicine. Acad Emerg Med 1999;6(4):348-51.

14. Stern SA, Kim HM, Neacy K. The impact of environmental factors on emergency medicine resident career choice. Acad Emerg Med 1999;6(4):262-70.

15. Henderson SO, Brestky P. Predictors of academic productivity in emergency medicine. Acad Emerg Med Off $\mathcal{Z}$ Soc Acad Emerg Med 2003;10(9):1009-11. 